Научная статья

УДК 101

DOI: $10.18101 / 1994-0866-2021-3-86-97$

\title{
ПРЕД-ПОЛОЖЕННОСТЬ ФИЛОСОФСКОГО ТЕКСТА: ОТ ИСТОРИИ К ЦИФРЕ
}

\section{(C) Шамшурин Алексей Андреевич}

аспирант 3-го года обучения, ассистент,

Удмуртский государственный университет

Россия, 426034, г. Ижевск, ул. Университетская, 1/1

shamshurin19aleksey@gmail.com

\begin{abstract}
Аннотация. В данной статье рассматривается философский текст в структурах предзаданности. Обозначается начало текста как пред-текст. Вхождение в текст полагает структуры «пред-», которые размечают поле мышления. Он существует на границе между предшествующим контекстом и последующей мыслью. В рамках философского метода субъект-объектного тождества задается направление от «пред-» к тексту. Обращение к пред-тексту позволяет понимать его как историю и кон-текст. Возникает два способа объективации - классика и традиция. Классика предъявляет «эталонное» понимание текста в рамках одной общей традиции смысла. Так обнаруживается нехватка иных смыслов вне традиции. Классическое понимание «предшествования» может быть проанализировано через концепт «ризома» (Делез). Цифровое пространство, существующее как ризома, становится новым вариантом предшествования для создания философского текста. Пред-текст становится цифровым гипертекстом. Он состоит из множества текстов, отсылающих друг к другу в виде скольжения по гиперссылкам. Пред-текст манифестирует пред-заданное начало мышления, разворачивающееся в тексте. В концепте «классика» субъективность задается «абсолютным субъектом». В классическом понимании истории субъективность задается «абсолютным субъектом». Современное представление структур предшествования выделяется «номадическим субъектом». Ризомное бытие цифрового текста предопределяется «присутствующим субъектом». Таким образом, предтекст вводит смысло-положенность и указывает на присутствие субъекта в теле философского текста.
\end{abstract}

Ключевые слова: пред-текст, философский текст, язык, введение, предзаданность, мышление, традиция, контекст, классика, ризома, цифра, история, субъектобъектное тождество.

Благодарности. Работа выполнена под научным руководством кандидата философских наук, доцента, заведующей кафедрой философии и гуманитарных дисциплин ФГБОУ ВО «Удмуртский государственный университет» Поляковой Натальи Борисовны.

\section{Для цитирования}

Шамшурин А. А. Пред-положенность философского текста: от истории к цифре // Вестник Бурятского государственного университета. Философия. 2021. Вып. 3. C. $86-97$. 
Возможность вхождения в философию предполагает обращение к ее содержанию, тем смыслам, которые раскрывают ее, делают «доступной для понимания». Но ухватить смысл философии, раскрыть метанарративные структуры интерпретации бытия-в-целом, репрезентируемые в философских текстах, позволяет лишь философский язык. Обращаясь к текстам о самой философии, о философских системах, можно обнаружить, что в их названиях встречается слово «введение». К ним относятся следующие известные работы: «О существе человеческой свободы. Введение в философию» и «Введение в метафизику» М. Хайдеггера, также две монографии К. Ясперса «Введение в философию» и «Всемирная история философии. Введение»; «Философско-историческое введение» Н. Гартмана и др. Сюда же относятся статьи «Введение к работе М. Хайдеггера "Исток художественного творения"» Г. Гадамера; «Введение к "Идеям I" Э. Гуссерля» П. Рикера; «Введение в структурный анализ повествовательных текстов» Р. Барта и др. Интересна ранняя работа М. Фуко «Введение к: Бинсвангер Л. Сон и существование» [1], объем которой превышает текст самой статьи, в чем замечается нехватка и несоответствие формы введения его смысловому содержанию. В том числе к перечисленным произведениям стоит добавить известный сборник статей «Введение в психоанализ» 3. Фрейда, поскольку в этом тексте речь идет о самостоятельной философской системе. А также труды типа «Введение в Лакана» В. Мазина; «Введение в чтение Гегеля» А. Кожева; «Колодец и пирамида: введение в семиологию Гегеля» Ж. Деррида и др., в которых интерпретируются взгляды тех или иных философов. Примечательно название исследования С. Л. Библера «От наукоучения к логике культуры. Два философских введения в XXI век». Слово «введение» в названиях работ встречается и ранее, например, «Введение к наброску системы натурфилософии» Ф. Шеллинга, «К критике гегелевской философии права. Введение» К. Маркса и др. С однотипным названием в большом количестве встречаются учебники по философии разных лет.

Деструкция такой формы философского изложения языка, как «текст», позволяет сделать вывод, что «введение» существует, во-первых, как его часть, то есть структурный элемент, стоящий перед «Основным текстом» и «Заключением». Во-вторых, как самостоятельное произведение о философии, что свидетельствует о наличии философии о философии, а именно о саморефлексии философии. Это последнее и создает пространство пред-положенности текста, где философствованию предшествует уже данная философия в ее истории как некий результат. Так, субъект самоопределяется в поле философского знания. Появляется необходимость вводить преломление объективно данной исторической положенности философии через «точку зрения» субъекта.

Для того чтобы раскрыть смысл «введения» как особого вида текста (предтекста), был проделан этимологический разбор. В результате выявлено три варианта перевода, через которые задаются значения слова «введение».

Первый вариант. Возможно, «в-ведение» происходит от французского слова «introduction», которое означает действие внесения чего-либо куда-либо, интеграцию или вставку чего-либо в единое целое. В этом же значении встречается в биологии как «заселение» или «внедрение» на территорию не типичного для 
данной местности вида растений или животных ${ }^{1}$. То есть «введение» как интродукция - это прежде всего действие, акт внедрения в среду с последующим ее освоением. Так, например, название работы «Introduction à l'architexte» («Введение в архитекст», 1979) Ж. Женнета имеет значение действия «ввести внутрь» архитекста, или «Introduction à la psychanalyse» (Введение в психоанализ, 1916-1917) 3. Фрейда ${ }^{2}$. Французское слово «introduction» является калькой латинского слова «introductio», буквально означающее «введение внутрь», но также имеющее значение «рекомендации» ${ }^{3}$.

Другим словом в латинском языке, означающим «введение», является «praefatio». «Рrae» - буквально «впереди, перед; из-за». «Praefatio» ближе по значению к «введению» как элементу структуры текста. Наиболее точным переводом является «предисловие», «вступительное слово», «вступление». Данное слово использовалось также для того, чтобы предварительно отметить в обращении к человеку его титул и звание ${ }^{4}$. Сегодня префация остается термином христианской литургии.

Третьим значением исследуемого слова, находящим истоки в греческом языке, является «prodromus». Примером здесь может служить работа М. В. Ломоносова «Prodromus ad verum Chimium Physicam» (Введение в истинную физическую химию, 1752). Интересно, что древнегреческое слово

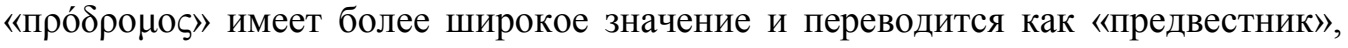
«посланник». В таком случае «введение» понимается как предварительная работа, предшествующая дальнейшей более систематической целостной работе. Часто «prodromus» можно встретить в названиях естественнонаучных исследований. Кроме того, «введение» встречается в религиозном дискурсе - святой Иоанн Предтеча (Креститель) носил это слово в качестве имени. По-гречески его имя

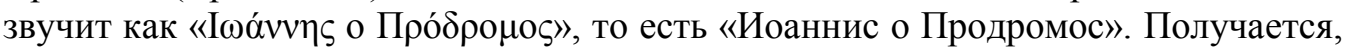
что, опираясь на значения слова «введение» - «интродукция», «префация», «продромуса» - в названиях письменных трудов, мы можем заключить о проблеме исходной точки понимания как объяснения, которая положена перед любым пониманием.

Анализ значений категории «введение» позволяет экстраполировать выводы на исследование философских текстов как на проблему предпонимания. Существует необходимость философа задать общие структуры своего видения, которые бы позволили интерпретировать/понимать «основной» текст. Проблема пред-текста - это проблема in medias res («в середину дела»/«в самую суть»). Данное рассуждение приводит к актуализации структуры «пред-», в качестве которой можно рассматривать не только разного рода «вве-

\footnotetext{
${ }^{1}$ Dictionnaire de français // Larousse.fr. URL: https://www.larousse.fr/dictionnaires/ francais/introduction/44007 (дата обращения: 18.04.2021). Текст: электронный.

${ }^{2}$ Encyclopédie // Larousse.fr. URL: https://www.larousse.fr/encyclopedie/ rechercher/introduction (дата обращения: 18.04.2021). Текст: электронный.

3 Латинский словарь // latin.slovaronline.com. URL: https://atin.slovaronline.com/ search?s=introductio (дата обращения: 18.04.2021). Текст: электронный.

${ }^{4}$ Там же.
} 
дение», но и «вступление», «предисловие», «начало», «основание», «пропедевтика» и др. Соответственно этому предположенность текста задается через «предтекст», понятие того, что́ перед текстом. Таким образом, этимологический анализ названий философских текстов в рамках герменевтического подхода позволяет расширить предмет исследования статьи до концептуализации «текста» как такового.

Заявляя «пред-текст» как точку разворачивания целого, он предстает в своей неопределенности как множественности смыслов. Поэтому предварительно стоит обозначить «пред-текст» в виде простой конструкции - «все то, что перед текстом». «Все» есть сущее, определенное языком и входящими в него значениями и смыслами, которые передаются через поколения. Целью исследования представленного в статье является рассмотрение философского «текста» в структурах его предположенности языком и традицией.

Все то, что перед текстом, мы можем рассматривать как существующее в пространстве и во времени. В пространственном отношении пред-текст располагается перед разворачиванием мысли и выводами. То есть он является частью перед другими частями целого, причем такой частью, где обычно прописываются актуальность, проблема, обзор литературы по теме, методы и цель исследования. Это указывает на жесткую форму пред-текста, подчиненную требованиям со стороны структуры. Одновременно с этим во введении как бы задается разметка всего текста на главы. А значит, что «Введение», само подчиняясь структуре, эту же структуру распространяет на весь текст. Стало быть, структура находится вне суммы частей - она трансцендирует.

Во временном отношении пред-текст уже не есть то, что мы могли бы назвать частью текста, поскольку «пред-» в этом случае становится пред-шествованием текста во времени. Пред-текст - это «прошлое» текста, предъявляющее его смысл целиком, как он есть. Предшествование как «прошлое» текста есть желание. «Ваш лепечущий текст по сути своей остается фригидным, как и всякая потребность, до тех пор, пока в нем не возникнет желание» [2, с. 464]. Р. Барт указывает на желание как на то, «что позволяет родиться акту письма (и чтения)» [Там же, с. 464].

Желание в предшествовании совпадает с нечто, которое явлено мыслью. Это нечто есть мыслящее мышление - мышление, направленное на самое себя и обнаруживающее себя как результат мыслительной деятельности. Итог предстает как (само)описание, а значит, как знание. Тогда пред-текст предъявляет состояние текста. Он тождествен рефлексии и самообнаружению.

Предшествование философского текста есть не что иное, как философская рефлексия. Философствующий субъект артикулируется в саморефлексии как разворачивание структур «пред-». Получается, что временное отношение предтекста к тексту указывает на субъект, субъективность которого объективируется по мере «шествования» от «пред-» к тексту. Причем эта структура «пред-» мыслится философствующим субъектом как предрассудок в том смысле, на который указывает Х.-Г. Гадамер [3]. Он предполагает не негативные, а позитивные коннотации предрассудка, тем самым открывая возможности чтения и интерпретации текста. Обнаруживая предрассудок, мышление не может отказаться от него, 
поскольку предрассудок есть результат самообнаружения мышления. Предзаданным является и сам язык мышления, с помощью которого оно присутствует и становится возможным как само-со-знание. Иначе говоря, происходит соединение с историей разворачивания философствования. Отсюда становится очевидной связь структуры «пред-» с традицией.

Поскольку философ пишет введение или пред-текст, постольку предрассудок и пред-заданный язык мышления ограничивают его субъективность. «Все то, что перед текстом, не может поместиться в текст. Это означает, во-первых, что предзаданное является местом положенности текста. Философ может еще не приступить к «изготовлению концептов» (Делез, Гваттари), а место для концепта ужеесть. Значит, не заполненное, пустое место необходимо как точка отсчета. У философа появляется потребность «расчистить» место, для чего и служит введение. Так можно предварительно задать его смысл. Другими словами, в пространственно-временном отношении пред-текст есть философствующий субъект, располагающий себя в качестве «нулевой точки». В этом плане пред-текст оказывается пустым, а как «ноль» - неопределенной определенностью. Так, время с помощью нуля становится пространством или опространстливается (time become to space).

Во-вторых, пред-заданное как бы обрамляет потенциальность будущего концепта еще до его актуализации. Space become to time - пространство становится временем. Процесс этого обрамления, точнее, само это обрамление, как представляется, и есть возникновение концепта - определенной неопределенности. Уже-существующие языковые рамки будут определять философствование субъекта, иначе последний будет лишь «растекаться мыслью по древу». Можно сказать, что предрассудок и язык определяют субъективность субъекта, и субъективностью же определяются в ответ. Субъективность как бы реализуется в обрамлении пред-заданного.

Как видим, возникает нехватка места для новых смыслов, которые относительно рамок являются как бы излишними, через-мерными. Тогда философ обращается к разным смыслам, которые в своей множественности уже представлены традицией, историей, контекстом в философском языке. Обращаясь к смыслам, философствующий субъект не выпадает из истории или традиции, он сам становится их частью, мерным/умеренным. Так, для последующего/постшествующего философа пред-шествующий будет также являться в определенной мере уже-данным или традицией. Традицией настолько, насколько воспринято пред-шествующим пред-заданное в качестве, как мы заключили, предрассудка и уже-существующего языка мышления. В каком-то смысле философ должен быть равен пред-заданному, то есть должен быть связью своей субъективности в виде концепта/текста и данной объективности как традиции. Связанный традицией философ в процессе саморефлексии должен стать связью с традицией или соединением с ней. Из чего следует, что пред-текст в субъективации традиции означает кон-текст («со-» от лат. «кон-»). В традиции заключено множество смыслов, которое сразу мыслится как единое, то есть со-единенное. Единство множества определяется традицией. 
Таким образом, пред-текст как кон-текст в своей неопределенности находит себе форму с помощью языка в виде знаниевых структур, то есть эпистемологически определяется. Формы объективации пред-текста приводят к представлению о нехватке смысловых структур. Когда множественность и избыточность субъективности саморефлексируются, она самообнаруживает саму себя как форму, недостаточную для выражения содержания. При этом субъективация мыслится как обращение (анамнез) в «прошлое» текста, в его состояние на уровне идеи. Пред-текст оборачивается определенной неопределенностью.

Субъект как точка пересечения смысловых потоков, со-единяя языковые формы и смысловые истории в процессе философствования, становится традицией, как бы реализует эту традицию собой. Философский язык в его со-единении с историей философии для каждого отдельного философствующего субъекта неизбежно выступает в качестве традиции. Вопрос традиции помещает в себя проблему многозначности пред-текста, поскольку традиция задает и то, как будет толковаться слово «введение», и то, как будет пониматься историко-культурный кон-текст.

Традиция связана не только с употреблением значения, но и со смыслом. «Самосознание и автобиография, из которых исходит Дильтей, не изначальны и не могут служить основой для герменевтической проблемы, ибо приватизируют историю. В действительности не история принадлежит нам, а мы принадлежим истории» [3, с. 329]. И далее: «наипервейшим из всех герменевтических условий остается, таким образом, предпонимание, вырастающее из нашей обращенности к тому же делу [A. Ш.: имеется в ввиду традищия]. Это решает вопрос о том, что может быть осуществлено в качестве целостного смысла <... . Итак, смысл сопринадлежности, то есть момент традиции в историко-герменевтической установке, осуществляется благодаря общности основополагающих предрассудков» [Там же, с. 329].

Пред-текст как кон-текст задает текстовую целостность. Он соединяет один философский текст с другими, что напоминает некую «цепь» текстов, совпадающую с историей философии, то есть «цепное письмо» (П. Слотердайк). Традиция задает единый и общий смысл, исходя из которого философствующему субъекту только и возможно прочтение или интерпретация. И тогда задачей философа будет возвратить смысл самой традиции, чтобы не быть подчиненным тому смыслу, который она полагает. Получается круг: от традиции смысла к смыслу традиции, и - снова. Пред-текст в методе субъект-объектного тождества соединяет традицию и смысл [4], которые разворачиваются в классической линейной определенности и ризомной не-линейной подвижности.

С точки зрения времени идиома «классика вечна» предъявляет сущность классики. Традиционный смысл в форме классики как бы застывает в истории, становится историческим в широком значении этого слова. Возьмем и обратную идиому «уйти в историю», что значит пропасть, исчезнув без следа. Так намечаются две границы: одна по эту сторону истории, а другая по ту ее сторону. Из этого следует, что классика может выступать в качестве эталона, который разграничивает историю от не-истории; то, что существует как историческое или не существует для нас, то есть «ушло в историю». 
Так, например, немецкая классическая философия приобретает черты традиции разнообразного, но единого и общего смысла, который оказывается господствующим в истории немецкой философии примерно с середины XVIII до середины XIX в. Вся пред-шествующая философия становится связанной конкретной традицией смысла. Одним из фактов этого является описание соединения логического и исторического методов у Гегеля, которое рассматривается Е. П. Ситковским в его вступительной статье к первому тому «Энциклопедии»: «Категория бытия раскрывается в философии Парменида <..>; категория ничто разработана в китайской и индийской философии; категория становления связана с философией Гераклита; категория для-себя-бытия - c атомистикой Демокрита; количество - Пифагор; мера - Протагор; категория сущности раскрывается в философии Платона; категория понятия - в философии Аристотеля; философия стоиков, скептиков, эпикурейцев соответствует понятию субъективности; философия Плотина - категории конкретной идеи; новая философия - основным разделам гегелевской «Феноменологии духа»; философия Декарта соответствует сознанию; философия Канта и Фихте - самосознанию; философия Шеллинга соответствует разуму; в философии самого Гегеля раскрывается абсолютное знание» [5, с. 36]. Как видим, из цитаты Е. П. Ситковского становится явной линейность «шествования» от «пред-» к тексту. В этом плане понятно, что не история объединяет, а господствующая традиция смысла. Тогда получается, что классика размечает пред-заданное в истории, делает из субъективности структур «пред-» и «со-» объективное и историческое. Традиция смысла также связывает настоящее и прошлое, конструирует смыслы настоящего в прошлом. Отсюда возможно рассматривать основания реконструкции прошедших событий в исторической науке. Уже-определенное настоящее накладывается на предшествующее неопределенное и целостное, вследствие чего вырисовывается понятие классификации - предел классичности и конец философии.

Классика как эталон есть мера, относительно которой вещь существует или не-существует в истории. Она дает человеку историю как единое целое, что приводит к линейности как судьбоносности и пред-определенности (лат. praedestinatio, prae-determinatio). Пред-определенность как раз и возникает из того момента, что уже-существующая традиция смысла пред-определяет еще-несуществующий смысл или виртуальный смысл. Так получается, что возможность появления какого-либо иного смысла вне традиции сразу исключена - «здесь мертвые учат живых», наподобие того, о чем писал П. Бурдье [6]. Отсюда, однако, обнаруживается и другое значение пред-определенности, а именно как предсказанное и пред-виденное. Различие между последними задается по способу явленности в слове или образе.

Такое «эталонное» мировоззрение создает видимость перспективы, простирающейся в будущее и тем самым как бы воспитывающее человека классикой. Это носит характер метонимии, то есть замещения целого частью. Так, определенное пред-шествует определяемому, один порядок другому, задавая линейность истории.

Традиция смысла легитимирует текст, разделяя его от другого. В таком случаe традиционное/классика различает старинное/историческое и современ- 
ное/актуальное. Современное потому «современно», что оно определено таковым по отношению к классическому эталону «пред-», который является фундаментальным для современности. Некоторые из множества текстов, не ставшие легитимными, отбрасываются и предаются забвению, то есть оказываются излишними. Вновь возникает нехватка смыслов. «Классический» пред-текст является пред-определенным, а философствующий субъект лишен свободы в выражении субъективности. Пред-текст, демонстрируя господствующий смысл, не принадлежит философу, поэтому снова возникает необходимость в саморефлексии.

Субъективацией эталонности будет концепт «ризома» (Делез), означающий отсутствие пред-заданного направления, нелинейность, фрактальность и творческий процесс. «Эталон» подразумевает «все»/сущее развитием и уточнением самого себя. Он есть истинная цель для своей копии. В отличие от него «ризома» полагает философию как «изготовление концептов» (Делез, Гваттари), когда дальнейший путь философствования не известен, не пред-определен. Само творчество становится путем и самоцелью. В этом плане противопоставляются классическое целенаправленное протягивание философской традиции и номадическое разрастание ризомы. Но вместе с тем последнее может занять место классики, пьедестал главенствующей традиции смысла. С точки зрения классики ризома есть еще один вариант формирования традиции в рамках единого, а с позиции номадического движения возникает смысловая множественность. Линейность это абстракция классической истории, а ризомность - написание в каждой точке нового исторического нарратива.

Возникает вопрос о другой форме пред-положенности текста, такой как цифра, заменившая в этом смысле историю и ее линейную ризомность, когда одна философская традиция сменяется другой. Если традиция вариативна и может быть представлена разными формами, то цифра предполагает инвариантность, и тогда она есть не форма, а жестко заданный формат. Поскольку в традиционной философии изменчивость форм происходит при незыблемости классического содержания, постольку в актуальном философствовании наблюдается смысловая подвижность в неизменном формате. Цифра предъявила нечто, что можно определить как ризомность линейности, что значит нелинейное и не-пред-сказанное возникновение смыслов.

Вместе с масштабной и массовой цифровизацией настал и конец классической единой и общей истории философии, которая с точки зрения абсолютного знания задавала одну философию, то есть один смысл. Бытие философии полагалось абсолютным субъектом. «История философии показывает, во-первых, что кажущиеся различными философские учения представляют собой лишь одну философию на различных ступенях ее развития; во-вторых, что особые принципы, каждый из которых лежит в основании одной какой-либо системы, суть лишь ответвления одного и того же целого» $[7$, с. 99]. В интернете как точке, в которой сжалось пространство и время, классифицировать, отбирать, забывать философские тексты становится невозможным или, по крайней мере, трудноосуществимым, так как они существуют в своей одновременности. Философия становится 
множественной, расширяющейся и неограниченной. А пред-заданное текста выступает как не-пред-определенное, то есть ризомное.

Кажется, что современному философскому тексту пред-шествует интернет, он же является со-единением с целым. «То, что дает нам интернет, - рассуждают У. Эко и Ж.-К. Карьер, - это на самом деле сырая информация, недифференцированная, неклассифицированная; кроме того, здесь нет никакого контроля над источниками. Однако каждому человеку необходимо, чтобы у него была возможность не только проверить знания, но и придать им смысл, упорядочить их, поместить в собственную систему понятий. Но какими критериями руководствоваться? <..> Так что нам необходима точка отсчета или, по крайней мере, несколько ориентиров, чтобы как-то подступиться к этому бурному океану знаний» [8]. Из цитаты ясно, что авторы понимают «пред-текст» как «интернет». Но если точкой отсчета в классической системе координат являлось «пустое» место, обрамленное предрассудком и языком, то интернет и цифра его заполняют. Субъективность философа объективируется цифрой, делая субъекта определенным. Она не предполагает пустоту и ничто. Субъективность в полноте определенного предъявляет себя как пересечение, наложение одного на другое либо же конструирование.

Слово, образ стали цифрой, в общем цифровым стал язык. Из этого следует, что и текстовая пред-положенность как языковая реальность стала цифровой. $\mathrm{B}$ цифровом мире техника производит посредством цифры. Современная техника достигает высоких скоростей переработки информации, и кажется, что реальность уже недоступна человеку. Она слишком быстра. «Информация начинает циркулировать повсюду со скоростью, равной световой. Нет больше абсолюта, который был бы мерой для всего остального» [9, с. 22]. Поскольку нет меры, то через-мерность повсюду. Ж. Бодрийяр определяет ее как гипертельность - то, что существует за пределами своей финальности. Поэтому каждый присутствующий в интернете может черпать смыслы из цифровой через-мерности, становясь субъектом посредством их пересечения в процессе самоконструирования субъективности.

Используя категории Ж. Бодрийяра, можно задать смыслы через обращение к не-пред-неопределенности, то есть цифровой ризомности. Таким образом, история философии гипертельна, значит, нет неопределенного предрассудка и языка мышления для текста, но есть только множество текстов как таковых. Больше нет никаких противоположностей (Ж. Бодрийяр): не бессмыслицу мы будем противопоставлять смыслу, а еще более осмысленное, чем сам смысл, - плеоназм, текстовое наслоение и разрастание текста. «Расползающаяся, выпячивающаяся, разрастающаяся, гипертельная: такова инертная судьба перенасыщенного мира» $[9$, c. 15].

Множество текстов посредством гиперссылок и гипер-разметки связываются друг с другом, образуя гипер-текст или единый текст-тело. Здесь нашли свое место технологии wiki - гипертекстовая среда для сбора и структуризации текста ${ }^{1}$.

1 Концепция wiki. URL: https://www.ph4.ru/wiki_index.php (дата обращения: 18.04.2021). Текст: электронный. 
Перед текстом как бы всплывает другой текст, который отсылает к третьему. Скольжение от одного пред-текста к другому как от одного знака/симулякра к другому, от одной цифры к другой есть «цифровое скольжение», или диджитал существование. Каждое отдельное слово может повлечь за собой нескончаемый поток информации. Поисковый запрос как взаимодействие человека с интернеттехнологией также работает только на уровне текста.

Цифровое тело текста позволяет увидеть то, что всегда было невидимо, «чистые» структуры мышления. Они возникают в результате «вычищения» цифрой субъективности и осмысленности. Это результат объективации - оцифрованный смысл как цифровая классика или цифровая традиция смысла, через которые цифрой «выложен» предрассудок. Не секрет, что компьютерные технологии повторяют мыслительный акт человека. Экран как бы читает наши глаза и мелкую моторику рук.

«Я» есть точка, которая задает скольжение в виде гипер-разметки текста, соединяя их через гиперссылки, образовывая тем самым совокупности текстов в конструкции, сайты, платформы. Со-единение множества уже не задается общим смыслом. Оно наличествует как выделенное гиперссылкой слово-знак, обращение к которому равнозначно отсылке к другому тексту-цифре. Такая само-предположенность указывает на множество единого. Иначе говоря, цифровая объективация предположенности текста есть мыслительная недостаточность. Нет общего смысла, есть текст и скольжение по нему. Из чего следует потребность в возвращении смысла, а значит, в обращении к структурам «пред-».

«Смысл есть то структурированное предвзятое, предусмотренным и предрешением в-видах-чего наброска, откуда становится понятно нечто как нечто» $[10$, c. 178]. Другими словами, в со-единении или связи мы обнаруживаем «пред»/《со-». Но как обнаружить «со-», когда одно слово-знак отсылает к другому, один текст-цифра вставлен в другой, где местом перехода является сам оцифрованный текст - гиперссылка? Может ли случиться так, что плагиат как тотальный текст будет возникать с первого предложения, не наступит ли тогда конец философского текста?

Субъективировать цифровой текст означает обнаружить избыточность единичного множественного. Тогда необходимо различаются множество единого как мыслительная недостаточность в виде цифровой объективации и единичное множественное как избыточная смысловая субъективация в их тождественности.

Итак, пред-положенность философского текста — это история субъективности, которая описывается через предзаданность и рефлексию, предрассудок и язык, традицию и контекст, классику и ризому. Присутствующий, то есть находящийся при-сути философии, субъект в процессе объективации оказывается абсолютным (классика), а в процессе субъективации оборачивается номадическим (ризома). Шествование, возникшее из желания (Р. Барт), от «пред-» к тексту оцифровалось. История философии остается, как и язык, предрассудок. Меняется язык пред-заданного. Язык как традиционная форма есть историческая предположенность, а язык как цифровая форма - это диджитал пред-положенность смысла. Традицией предъявления текста становится цифровой формат (Microsoft Word версий 6.0, 7.0, 97), вне которой его как бы уже не существует. Цифра в 
качестве пред-положенности начинает писать новую историю субъективности. Эта новая структура «пред-» - цифровая ризома, цифровое тело текста, которое пред-положено к разворачиванию субъективности, когда необходимо человеческое присутствие как смысло-определяющее тело. «Все то, что перед текстом», оцифровано, а значит, через-мерность и перенасыщенность информации являет «пред-» как цифровую ризомность. Отсюда проявление свободы: свободы от пред-определенного и свободы для реализации субъективности через текст. Присутствие в цифровой реальности номадично, поэтому предполагает нулевую степень письма [11]. Мы не можем избавиться от языка и предрассудка так же, как и от цифры, но мы свободны в выражении желания создавать текст, что продолжает процесс конструирования присутствующим субъектом.

\section{Литература}

1. Фуко М. Введение к: Бинсвангер Л. Сон и существование // Ранние работы / перевод с французского и предисловие О. А. Власовой. Санкт-Петербург: Владимир Даль, 2015. С. 83-196. Текст: непосредственный.

2. Барт Р. Удовольствие от текста // Избранные работы: семиотика. Поэтика. Москва, 1994. С. 462-518. Текст: непосредственный.

3. Гадамер Х.-Г. Истина и метод: основы философской герменевтики / перевод с немецкого, под общей редакцией и вступительная статья Б. Н. Бессонова. Москва: Прогресс, 1988. 704 с. Текст: непосредственный.

4. Полякова Н. Б. Герменевтическая интерпретация «знания как бытия» // История. Семиотика. Культура: сборник материалов международной научной конференции, посвященной 250-летию Фридриха Шлейермахера (Самара, 23-24 ноября 2018 г.) / Самарский университет, ответственный редактор И. В. Дёмин. Самара: Изд-во Самар. гуманит. акад., 2018. С. 149-154. Текст: непосредственный.

5. Ситковский Е. П. Философская энциклопедия Гегеля // Гегель. Энциклопедия философских наук. Т. 1. Наука логики. Москва: Мысль, 1974. С. 5-52. Текст: непосредственный.

6. Бурдье П. Мертвый хватает живого. Об отношениях между историей овеществленной и историей инкорпорированной // Социология политики / перевод с французского, составление, под общей редакцией и предисловие Н. А. Шматко. Москва: Socio-Logos, 1993. С. 263-309. Текст: непосредственный.

7. Гегель Г. Энциклопедия философских наук. Т. 1. Наука логики. Москва: Мысль, 1974. 452 с. Текст: непосредственный.

8. Карьер Ж.-К., Эко У. Не надейтесь избавиться от книг! URL: http://www.pseudology.org/Eco_Umberto/Ne_nadeites_izbavi_ot_knig2.pdf (дата обращения: 18.04.2021). Текст: электронный.

9. Бодрийяр Ж. Фатальные стратегии / перевод с французского А. Качалова; научный редактор Д. Дамте. Москва: РИПОЛ классик, 2017288 с. Текст: непосредственный.

10. Хайдеггер М. Бытие и время: перевод с немецкого В. В. Бибихина. Харьков: Фолио, 2003. 503 с. Текст: непосредственный.

11. Барт Р. Нулевая степень письма: перевод с французского. Москва: Академический Проект, 2008. 431 с. Текст: непосредственный.

Статья поступила в редакиию 10.06.2021; одобрена после рецензирования 05.07.2021; принята к публикации 14.09.2021. 


\title{
PRE-POSITEDNESS OF A PHILOSOPHICAL TEXT: FROM HISTORY TO DIGITAL FORMAT
}

\author{
Aleksey A. Shamshurin \\ Research Assistant, \\ Udmurt State University \\ 1 Universitetskaya St., Izhevsk 426034, Russia \\ shamshurin19aleksey@gmail.com
}

Abstract. The article analyzes a philosophical text in the structures of pre-determinacy. The beginning of the text is defined as pre-text. Entry into the text suggests the structures "pre-" that mark the field of thinking. It exists on the border between the previous context and the subsequent thought. Within the framework of the philosophical method of subjectobject identity, a direction is set from the "pre-" to the text. Referring to the pre-text allows understanding it as history and con-text. There are two ways of objectification: classics and tradition. The classics present a "standard" understanding of the text within the framework of one common tradition of meaning. In such a way the lack of other meanings outside of tradition is revealed. The classical understanding of "precedence" can be analyzed through the concept of "rhizome" (Deleuze). The digital space, which exists as a rhizome, becomes a new variant of precedence for a philosophical text. The pre-text is becoming a digital hypertext. It consists of many texts referring to each other in the form of clicking through hyperlinks. The pre-text manifests a pre-determined beginning of thought that is unfolding in the text. In the concept of "classics", subjectivity is set by the "absolute subject". In the classical understanding of history, subjectivity is pre-determined by the "absolute subject". The modern representation of precedence structures is distinguished by the "nomadic subject". The rhizomal existence of a digital text is predetermined by the "present subject". Thus, the pre-text introduces the positedness of meaning and indicates the presence of a subject in the body of a philosophical text.

Keywords: pre-text, philosophical text, language, introduction, pre-determinacy, thought, tradition, context, classics, rhizome, digital format, history, subject-object identity

\section{For citation}

Shamshurin A. A. Pre-Positedness of A Philosophical Text: From History to Digital Format. Bulletin of Buryat State University. Philosophy. 2021; 3: 86-97 (In Russ.).

Acknowledgments. The article was prepared under the scientific supervision of Candidate of Science (Philos.), A/Professor, Head of Philosophy and Humanities Department of Udmurt State University Polyakova Natalya Borisovna.

The article was submitted 10.06.2021; approved after reviewing 05.07.2021; accepted for publication 14.09.2021. 